\title{
Learning, Reflexivity and Knowing from Within: Being Inspired by John Shotter Or Why isn't he wearing socks?!
}

\section{Ann Cunliffe}

EAESP-FGV - Brazil

ann.cunliffe@fgv.br

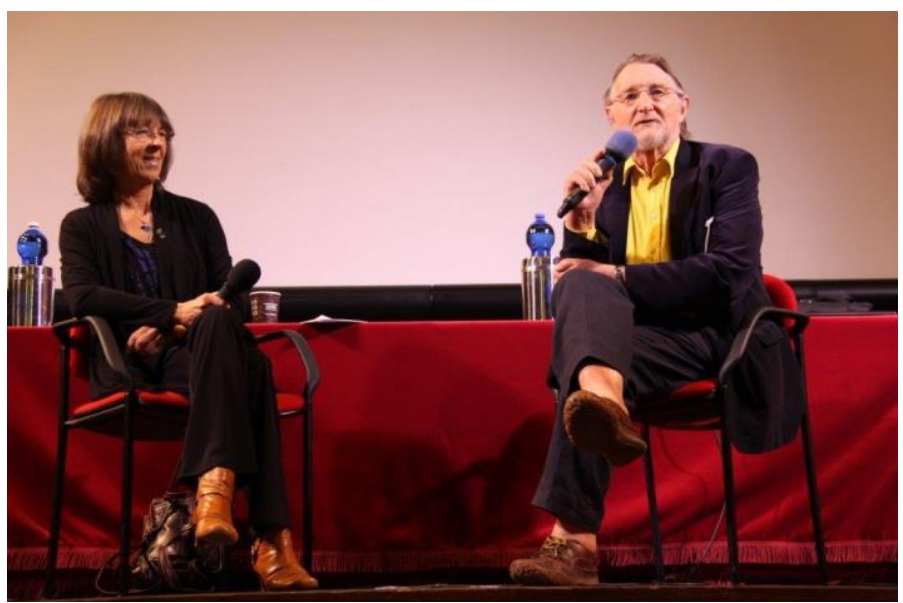

Abstract

A brief story and tribute for John Shotter.

Keywords: Learning, Reflexivity, Knowing, John Shotter 
Okay - it might look like I was wondering about the socks (or lack of them), but actually I was ruminating on Bakhtin's notion of heteroglossia ... Oh what the heck, I WAS thinking about the socks!

We were giving a conference keynote on 'Authorship Revisited' at the Organizational Learning, Knowledge and Capabilities Conference in Milan and I can't recall why he wasn't wearing socks - but I do remember thinking fondly that this was quintessentially John.... A nonconformist, a quiet radical, insightful, provocative, challenging, inspirational .... And sockless in the face of convention!

Over the years we have been friends, we had many conversations, usually whilst one of us was in another part of the world. And although none of them have been about socks, I always came away from our chats with another question, another idea to work through, or a different way of thinking about something. So although John may not have written directly on organizational learning, he embodied learning in terms of encouraging others to move beyond conventional thinking and by exploring different forms of knowledge, knowing and theorising. He continued to be curious throughout his life, and his work and ideas have inspired many people - both academics and practioners - over the last 45 years.

We met back in 1994, in New Hampshire when, as I wrote in my chapter in Tim Corcoran and John Cromby's 2016 book, Essays in Honour of John Shotter, I was inspired by twenty-one words he'd written on page 118 of Conversational Realities. Twenty-one words that made a difference to my way of thinking, my research, and my life:

"I shall take it that the basic practical moral problem in life is not what to do but [who] to be..."

These words are important because they call upon us to move away from mainstream ways of researching, teaching and being an academic, manager or leader. They ask us to start thinking about what it means to be human in the world - and being human means thinking about ourselves in relation with others. The need to think about these issues and about relationality is central to John's work. Let me explain....

John's early work (e.g., 1993) focused on a rhetorically-responsive form of social constructionism - on how we create and shape organizational 'realities' in our everyday conversations and interactions and how managers act as practical authors of those realities. He drew attention to the idea that organizations are not structures or systems, but relational landscapes shifting from the imaginary to the imagined. The 'imagined' consists of accepted 
social practices and ways of talking in particular settings, which we think are real but which we continually maintain and shape in our interactions. The University is an example of an imagined setting because it consists of a number of buildings and practices that include teaching, managing, or studying, which in turn bring with them certain ways of talking and interacting that context. However the uncertainty and fluidity of relationships and in conversations mean these practices are not fixed nor have real structure, they are always open to negotiation and change ... and this is the imaginary. So our conversations and interactions are a tentative balance between both. As John says:

"speakers must show in their speech an awareness of their 'place', their relatedness to the others around them, their status and the rights it allows them and the duties it places upon them;" [the imagined],

"but they must also construct opportunities accordingly in the course of their talk to be challenged ...." (Shotter, 1993, p. 94) [the imaginary].

This requires us to think about organizational learning in a different way, not as structures and systems but as exploratory conversations in which we reflexively question and challenge what we may be taking for granted in the way we see, manage, and work in organizations. We do so by being sensitive to the imaginaries, examining whether the imagined is a shared and fixed construction that might be limiting the way we do things in the organization, and creating a new possible imagineds in our imaginary talk. And this process is a relational one because it means we need to be responsive to our surroundings and to other people. From this perspective, organizational learning is therefore a conversational activity. In Conversational Realities Revisited (2008), John changes rhetorically-responsive to relationally-responsive, which moves from a focus on language to making sense of our experience as an intersubjective conversational activity, in which we contest and negotiate meanings in spontaneous, responsive, and practical ways. This does not mean that everything is open to interpretation because we live and work within language communities in which particular understandings and ways of speaking and interacting are sustained.

Relationally-responsive social constructionism means that we need to be careful and thoughtful in terms of our conversations with others and also requires us to think about knowledge in a different way. Much of organization and management theory focuses on 
$\underline{\text { what }}$ managers and leaders should $\underline{d o}$ and which organizational designs are effective - what structures, behaviours, actions, plans, strategies, roles and techniques should be employed to make managers good morally neutral technicians (Ghoshal, 2005) i.e., rational and efficient and effective. This is an objectivist approach to research - and to managing organizations (Cunliffe, 2011). Organizational learning (OL) scholarship often takes a similar approach. OL can be defined as:

"a change in the organization's knowledge that occurs as a function of experience" (Argote, 2011: p. 440).

"The study of the learning processes of and within organizations" (Easterby-Smith \& Lyles, 2003: p. 2).

OL is based on an organization's ability to create, retain and transfer knowledge and to develop experience and capabilities in order to be competitive. Research therefore focuses on the strategies, mechanisms, practices, tools, and systems required for learning to occur. John would say that much of this type of research is based on the "allure of generalized conceptualization" (2016, p. 52), which limits us because our theories and models determine what we then see and what we think should happen. Over the years, he has taken on conventional and generalized forms of referential knowledge, arguing instead for a knowing-from-within in which we come to understand our experience in our sayings and doings. Knowing-from-within is a more fluid, emergent, and ongoing knowing - a knowing 'from within' our experience, practice, language, culture, history, etc,. As we move around and are immersed within circumstances, actions, events and conversations, then we develop our skills as we become attuned to the constraints, nuances and opportunities in those circumstances. If we are to learn from within these circumstances then we need to explore possibilities - how we might reconfigure our understanding, explore where such possibilities may take us, and begin to talk and act differently. Knowing-from-within is also a relational knowing because understanding emerges from within our involvement with people. Thus, from a research perspective:

"Instead of turning immediately, as we have in the past, to a study of how individuals come to know the objects and entities in the world around them, we must begin in quite a different way: we must study how, by interweaving our talk with our other 
actions and activities, we can first develop and sustain between us different, particular ways of relating ourselves to each other.” (Shotter, 1996: p. 299)

So what form might learning take if we embrace John's ideas? Learning:

- Is dialogical. Communicating dialogically (Bakhtin, 1986) means that our utterances and responses in the moment of speaking are both open to a myriad of possibilities (centrifugal forces) and contain ideological ways of talking (centripetal forces) that may restrict our thoughts and speech. Learning dialogically means being open to others, to various voices and alternative meanings, and to the need for conversation and discussion. But this dialogue is a pre-conceptual way of speaking (not fixed by theories, models or principles) in which we are open to possibilities.

- Is about making a difference that matters in which "we can act to make a difference to the structure of the world that would not have occurred if we had not acted" (Shotter, 2016, p. 24). While this might imply learning and behavioural change as a form of conditioning and reinforcement that plays through old conventional learning theories such as Skinner's and Pavlov's, it is not so. John's view, I believe, gives us freedom to learn by questioning, challenging, exploring in active and proactive ways.

- At an organizational level, learning is also relational because it involves collective inquiry and reflexive dialogue. It involves a collaborative relationship between researchers and organization members, consultants and clients, and organizational members with the aim of mutual, but not always the same, learning. Relationally-responsive conversations mean being opening to each other, to different views and ways of talking (Cunliffe \& Scaratti, 2017).

- Learning may emerge from moments of 'being struck' and moved to change our ways of being, talking and acting. Being struck involves a spontaneous cognitive or visceral response to events or relationships occurring around us - "a feeling there is something important we cannot quite grasp in the moment" (Cunliffe, 2002, p.42) but that can be the basis for making new connections and constructing our sense of situations in new ways. Corlett (2012) argues that when we are 'struck' we may be so in "an embodied, tacit way and then draw on practical or explicit knowledge to help make sense" (p. 465) and if we engage in reflexive dialogue when drawing on this knowledge/knowing, then learning occurs. 
- We construct these new ways by articulating our experience into a landscape of possibilities by seeing features that may not have been noticed or responded to previously. How might this occur? It happens practically as we “"move around' from within our living immersion, from within our engagement with these circumstances - sensing a fragment here at this moment in time, another fragment there at that moment in time - we gradually come to a unitary sense of a 'something's' particular nature in 'its' mattering to us" (Shotter, 2016, p. 91. Italics in original). Creating a new landscape within organizational learning involves constructing meanings in relational ways, which requires participants to become skilful in enacting relationallyresponsive conversations (Larsen \& Madsen, 2016).

There are examples that draw on this way of conceptualizing learning. Peter Senge's work on organizational learning does draw attention to dialogue but not in the same fluid, relational sense as John: dialogue is seen in terms of a progression of stages (Senge, et al, 1994: p. 359-364). Kevin Barge and Martin Little (2008) build on John's work, arguing that mutual learning occurs when there are "reflexive relationships among communication, meaning, action, and context as embodied persons engage each other within the flow of conversational activity" (p. 505). While not directly about organizational learning per se, Gervais Bushe and Robert Marshak's (2015) edited book on Dialogic Organization Development embraces a social constructionist philosophy to frame organizations as emerging systems of meaning-making in talk, multiply understood and co-produced. Various chapters in the book include: how co-inquirers can develop a dialogic sensitivity; how to create coherent and convincing narratives; how transformative learning occurs in dialogue, how to craft appropriate questions; and how to amplify new narratives and generative images.

John Shotter's ideas are being taken forward, both theoretically and practically. To return to those 21 words - if we embrace the idea that the practical moral problem in life is who to be, then learning, and our responsibility for learning and creating ethical and responsive organizations takes on new meaning. Learning means exploring possibilities and creating new organization landscapes in our relationally-responsive conversations with others.

And the socks ..... or lack of them ..... were a moment of 'being struck' for me, for I realized in that moment that if I hadn't read Conversational Realities back in 1994, or met John, my learning over the course of my career would be improvished. My research would 
have taken a more positivistic approach. In other words, I'd probably be sitting in an office somewhere - wearing compression socks - generating nice little propositions, models and theories, and being bored out of my mind! 


\section{References}

Argote, L. (2011) Organizational learning research: Past, present and future. Management Learning, 42(4), 439-446.

Barge, J. K. \& Little, M. (2008) A discursive approach to skillful activity. Communication Theory, 18(4), 505-534.

Bushe, G. R. \& Marshak, R. J. (Eds.). (2015) Dialogic Organizational Development: The Theory and Practice of Transformational Change. Oakland, CA: Berrett-Koehler Publishers.

Corlett, S. (2012) Participant learning in and through research as reflexive dialogue: Being 'struck' and the effects of recall. Management Learning, 44(5), 453-469.

Cunliffe, A. L. (2002) Reflexive dialogical practice in management learning. Management Learning, 33(1), 35-61.

Cunliffe, A. L. (2011) Crafting qualitative research: Morgan and Smircich 30 years on. Organizational Research Methods, 14, 647-673.

Cunliffe, A. L. (2014) A Very Short, Fairly Interesting and Reasonably Cheap Book About Management. (2. ed.) London: Sage Publications.

Cunliffe, A. L. (2016) Twenty-one words that made a difference: Shifting paradigms. In T. Corcoran \& J. Cromby (Eds.). Joint Action: Essays in Honour of John Shotter. Taylor \& Francis’ Psychology Press, Explorations in Social Psychology. (pp. 173-190).

Cunliffe, A. L. \& Scaratti, G. (2017) Embedding impact: Developing situated knowledge through dialogical sensemaking. British Journal of Management, 28(1), 29-44.

Easterby-Smith, M. \& Lyles, M. A. (2003) (Eds.). Handbook of Organizational Learning and Knowledge Management. Malden, MA: Blackwell Publishing.

Ghoshal, S. (2005) Bad management theories are destroying good management practices, Academy of Management Learning and Education, 4(1), 75-91. 
Larsen, M. V. \& Madsen, C. O. (2016) Exploring how social poetics can be used to understand processes of management learning. Management Learning, 47(5), 489-505.

Senge, P., Kleiner, A., Roberts, C., Ross, R., \& Smith, B. (1994) The Fifth Discipline Fieldbook. New York: Currency Doubleday.

Shotter, J. (1993) Conversational Realities: Constructing Life through Language. London: Sage.

Shotter, J. (1996) Living in a Wittgensteinian World: Beyond Theory to a Poetics of Practices. Journal for the Theory of Social Behaviour, 26(3), 293-311.

Shotter, J. (2008) Conversational Realities Revisited: Life Language, Body and World. Chagrin Falls, OH: Taos Institute Publications.

Shotter, J. (2016) Speaking Actually: Towards a New 'Fluid' Common-Sense Understanding of Relational Becomings. Farnhill, UK: Everything is Connected Press 